\title{
Computer simulation in production process of wiper blades for cars
}

\author{
Justyna OGORZAŁEK
}

DOI: 10.30464/jmee.2019.3.2.131

Cite this article as:

Ogorzałek J. Computer simulation in production process of wiper blades for cars. Journal of Mechanical and Energy Engineering, Vol. 3(43), No. 2, 2019, pp. 131-138.

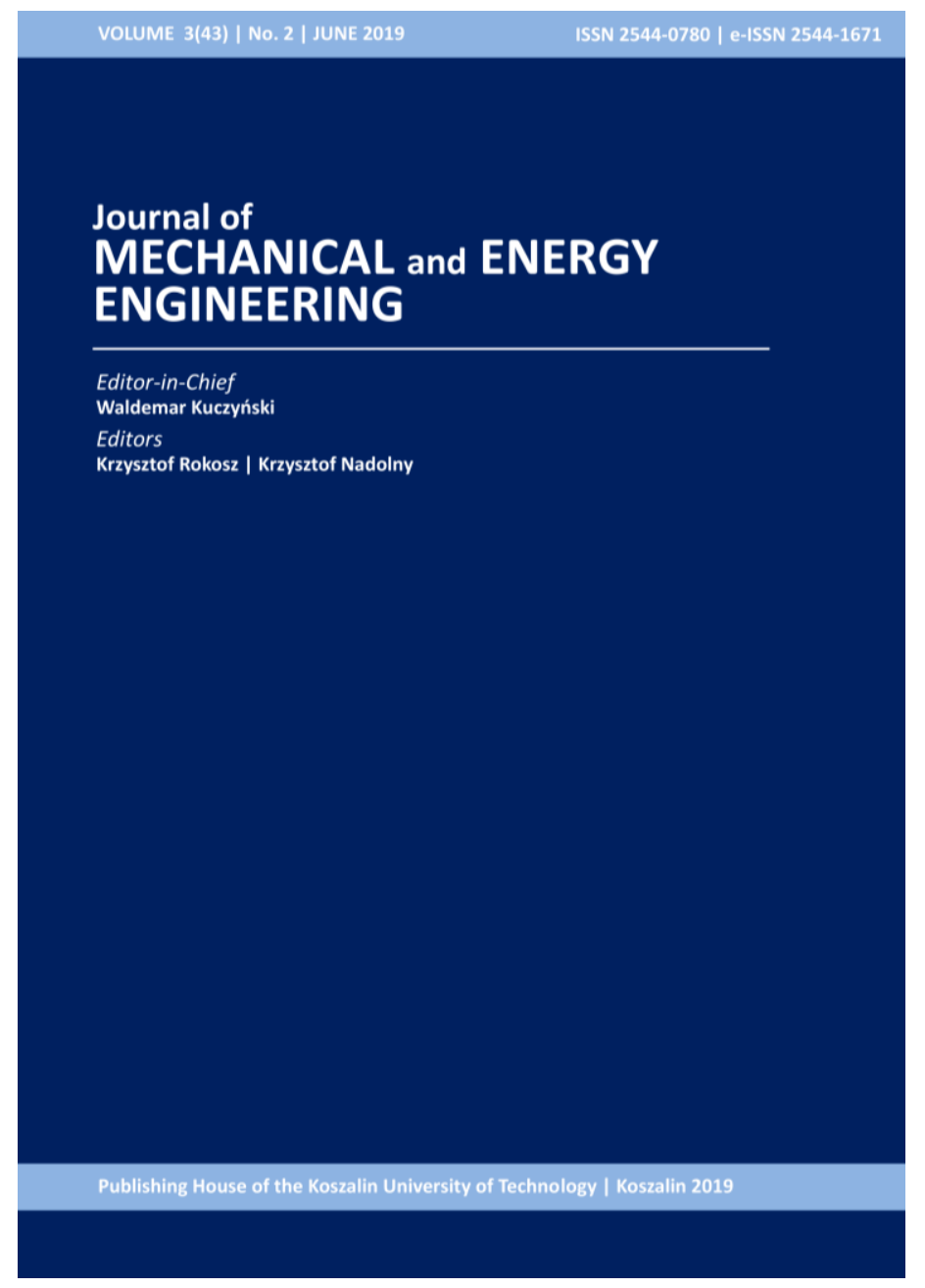

Journal of Mechanical and Energy Engineering

Website: jmee.tu.koszalin.pl

ISSN (Print): 2544-0780

ISSN (Online): 2544-1671

Volume: 3(43)

Number: 2

Year: 2019

Pages: 131-138

Article Info:

Received 29 May 2019

Accepted 5 June 2019

\section{Open Access}

This article is distributed under the terms of the Creative Commons Attribution 4.0 (CC BY 4.0) International License (http://creativecommons.org/licenses/by/4.0/), which permits unrestricted use, distribution, and reproduction in any medium, provided you give appropriate credit to the original author(s) and the source, provide a link to the Creative Commons license, and indicate if changes were made. 


\title{
COMPUTER SIMULATION IN PRODUCTION PROCESS OF WIPER BLADES FOR CARS
}

\author{
Justyna OGORZAŁEK ${ }^{1 *}$ \\ ${ }^{1 *}$ Faculty of Mechanical Engineering, Department of Production Engineering, Koszalin University of \\ Technology,Raclawicka 15-17, 75-620 Koszalin, Poland, e-mail: justyna.ogorzalek95@gmail.com
}

(Received 29 May 2019, Accepted 5 June 2019)

\begin{abstract}
The article presents the most important information concerning computer modelling and simulation, system dynamics modelling, discrete event modelling and agent modelling. An exemplary model of the production process of windscreen wipers, which was created on the basis of assumptions, discussed the individual components of the model. An example of using JAVA code in AnyLogic program is presented and examples of indicators that can be calculated and presented in the form of a graph in the program are shown. Computer simulations enable tracking and analysis of the production process. They help to verify assumptions and detect irregularities in the modeled process. Simulation programs have a wide range of possibilities, allow you to create reports, charts, comparisons, allow you to optimize processes.
\end{abstract}

Keywords: numerical simulation, production process, wiper blade, agent modeling, discreet modeling, system dynamics

\section{INTRODUCTION}

Computer modelling is a way to solve real problems, but most often you can't afford to experiment on real objects. One of the public and simple modelling tools is Microsoft Excel, which has several advantages: it is easy to use, widely available, and allows you to add scripts to formulas. Modeling, which is based on spreadsheets allows for quick results - values are entered into cells and output data are displayed in others. Very complex models allow for data optimization. Spreadsheets are used for scheduling, loading or unloading, as well as determining delivery times [2].

When it is difficult to obtain a solution with analytical methods on a real model, simulations and modelling are used. They make it possible to track and analyse the production process. They are also used to verify certain assumptions, which allows for the detection of irregularities. Production process modelling is based on the creation of a virtual computer model, which shows the real production system. During the simulation, various types of reports are obtained, which allow the development of further actions or improvement of the existing process. The computer model can be improved by adding more machines, workstations, warehouses, determining their capacity, which makes it possible to carry out further simulations and verify them [1].

Computer simulation models contain logic in their structure, presenting the behavior and mutual relations of individual elements of the system. The functioning of such a system can be presented graphically using animation [8].

Optimization of production structures applies to every company that wants to gain an advantage on the market. Already at the planning stage it is necessary to make decisions that will allow to maximize profits. Creating a good production process takes time, but it allows to shorten the time of operations and increase profits [4].

Combining optimization with modelling and simulation can form the basis for improvement of production systems, the difference between them is shown in Figure 1. The task in modelling is to find a simulation model, in the simulation - determination of results, and in the optimization - determination of input data [10].

\section{TYPES OF SIMULATION MODEL}

There are three types of simulation models that differ in the description of the variables. There are continuous modelling, discrete modelling and agent modelling. 


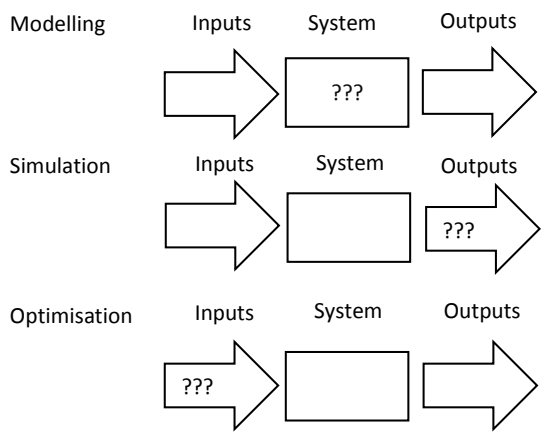

Fig. 1. The relationship between modelling, simulation and optimization [3]

\subsection{Modelling the dynamics of system}

The dynamics of the systems is a continuous simulation and is distinguished from discrete processes by the fact that it takes place in fixed conditions in which raw materials are supplied and received at the same time in an uninterrupted manner [5].

The elements that make up the dynamics of the systems are: the resource and the stream. There are also auxiliary variables, constants, functions and relationships. A resource is a size and defines the quantitative state. If it is a variable size, the term stream is also used. The resource is related to input and output streams [8].

An example of continuous simulation can be the simulation of physical phenomena, e.g. change of weather or gas flow around a rigid mass. The first continuous simulations were carried out using analogue machines [7].

\subsection{Modelling of discrete events}

Discrete simulation is a simulation in which system state variables change discretely. The passage of time in this system takes place through the sequence of events. Modelling in a discrete simulation is objectoriented modelling or modelling by means of a network of activities. Network models are Petri networks as well as evaluation networks. During the experiment, it is necessary to introduce uncertainty and randomness of the system. Then random values are introduced into the model according to a certain probability distribution by means of the Monte Carlo method. Application of the method consists of selection of random variables, selection of input variables, calculation of several observations (generation of random variables, determination of output variables, repetition of observations in the sample, determination of parameters of output statistics), and at the end of the calculation. There are several modelling tools in discrete simulation and these are [8]:

1. GPSS modelling language - the programming language of simulation, which has a process orientation. This language has elements such as object, commands, programming blocks and predefined variables SNA,

2. ExtendSim modeling system - with the help of this system it is possible to build models that are oriented towards processes, events or processes and events,

3. Arena modeling system - it is an integrated software for modeling and simulation, this system has universal elements used to describe any systems. Arena helps to model and simulate processes with different levels of complexity. Its basic functions include modeling, simulation, visualization and analysis.

\subsection{Agent modelling}

Agent modelling is currently used in many areas, including economy, management, technical and social fields. An agent can be a person, device, machine or software that performs a specific activity [8].

Agent modelling was created because of technological progress, which allowed to apply new methods of object-oriented modelling thanks to computer science. Faster processors and larger memory have been introduced to the market, and agent-based models are more demanding than system dynamics or discrete event modelling. Agents in agent modeling can take the form of e.g. Vehicles, equipment, products, organization, investments, ideas, as well as people in different roles [2].

An agent in information technology is a computer system that is placed in an environment is capable of responding in the environment to perform specific actions. Agent technology is used in anthropomorphic systems e.g. as virtual teachers, salesmen, actors in computer games. In order to build an agent system, an appropriate platform is needed, which should provide an agent management system. Artificial intelligence systems are used to support agent systems, which are based on inference rules, neural networks and genetic algorithms [8].

\section{EXAMPLE OF A SIMULATION MODEL}

Preparing a model and conducting a simulation involves costs. While preparing the model, one should strive to simplify it as much as possible, the model becomes more comprehensible and easier to analyze [9].

When creating a production process model, the process boundaries and the connection of the process with the environment should be defined (e.g. material deliveries, output of finished products), changeover of machines, programmed of possible downtimes, probable failures. It is also necessary to model workstations and their mutual relations by defining the flow of materials and information. The functioning of the process is presented graphically through e.g. 
animation, and after the simulation the results in the form of statistics are obtained [6].

The presented example of a simulation model was created in AnyLogic, which uses three modelling methods: system dynamics, discrete events and agent modelling. The software has a graphical programming interface and also uses a graphical modelling language, which allows to create a model using graphical elements, which can be further expanded through the Java programming language.

The production process concerns the production of windscreen wipers. Table 1 presents the assumptions for the simulation model. The time described in brackets is the time interval, which in the simulation is described by a triangular distribution. The first value is the minimum time, the next one is the intermediate time and the last one is the maximum time.

Production of wipers consists of several stages. The first one is to make a pen and spoiler on an extruder for rubber. Synthetic rubber is used in the production process. After leaving the extruder, the material is cut to the desired length. The second stage is profiling and cutting springs, which are located in the wiper arm. The third and final stage is the production of tips, clamping covers and central fixing using a plastic injection moulding machine. A doubleseat injection moulding machine is used, which allows for the production of a larger number of elements.

Tab. 1. Simulation process assumptions

\begin{tabular}{|c|c|c|c|c|}
\hline L.p. & $\begin{array}{l}\text { Machine/ } \\
\text { activity }\end{array}$ & $\begin{array}{l}\text { Time of } \\
\text { operations }\end{array}$ & $\begin{array}{c}\text { Ouantity } \\
\text { of raw } \\
\text { material g }\end{array}$ & $\begin{array}{c}\text { Price of the } \\
\text { raw } \\
\text { material } \\
\text { PLN/kg }\end{array}$ \\
\hline \multirow{4}{*}{1.} & Rubber extruder & & & \\
\hline & $\begin{array}{c}\text { Wiper blade } \\
\text { extrusion }\end{array}$ & 3,2 & 20 & 12 \\
\hline & $\begin{array}{c}\text { Wiper blade } \\
\text { spoiler extrusion }\end{array}$ & 3,2 & 30 & 12 \\
\hline & $\begin{array}{l}\text { Cutting the } \\
\text { wiper blade } \\
\text { spoiler }\end{array}$ & $(1,2,3)$ & - & - \\
\hline 2. & $\begin{array}{c}\text { Profiling of } \\
\text { springs }\end{array}$ & 10 & 60 & 4 \\
\hline 3. & $\begin{array}{c}\text { Cutting the } \\
\text { springs }\end{array}$ & $(9,10,11)$ & - & - \\
\hline \multirow{4}{*}{4.} & $\begin{array}{l}\text { Plastic injection } \\
\text { moulding } \\
\text { machine }\end{array}$ & & & \\
\hline & $\begin{array}{c}\text { End of wiper } \\
\text { blade }\end{array}$ & $(28,30,34)$ & 20 & 10 \\
\hline & Fixing cover & $(28,30,34)$ & 20 & 10 \\
\hline & Central fixing & $(28,30,24)$ & 20 & 10 \\
\hline 5. & Assembling & $(55,60,65)$ & & \\
\hline
\end{tabular}

Assumptions to the production process allow to determine the holding time of elements in individual blocks in the simulation program.

The production process of car wipers is shown in Figure 2. Two machines have been modelled, which can produce different elements when they are rearmed. All manufactured components are also stored in separate blocks, which allows for picking appropriate for assembly. In the process modelling, Java code was used, which allowed to model the changeover of the machines.

In the AnyLogic simulation program you can find a number of elements that allow you to create a process. The elements used to create the process are shown in Figure 2 and described below.

The elements 'elastomer', 'spring' and 'material' are the input elements of the model Agents are responsible for the generation of the raw material, which is then processed.

1. The elements 'changeElastomer', 'separateTypeElastomer', 'changeMateralPET', 'separateType' and 'splitFixture' are those elements which allow the separation of two activities and have two outputs. Very often they are used to sort two elements according to established criteria, for example as separation of a well and incorrectly made element or dividing elements according to the number of outputs to be output by one and the other output. In the presented model, the second solution was applied, because the machine changeover takes place after a certain number of pieces of detail is produced, so the AnyLogic program needs information about the change of the produced item.

2. Elements such as 'changeoverElastomer' or 'cutting' are elements that can hold the workpieces for a defined, fixed period of time. Very often they are used as machines to process workpieces when modelling production processes.

3. The "stopElastomer" and "stopMaterial" elements block material flow. In the presented model they are used because two elements are produced on one machine at a different time, so they allow to produce one element for another.

4. Elements such as "BufferSpoiler" or "BufferFixture" are known as "Queue", allowing you to store items. In production process modeling they serve as warehouses for semi-finished or finished products.

5. The "assembling" and "assemblingMaterial" elements are used as assemblies to allow several parts to be assembled into one.

The output element is the end point of the model. 


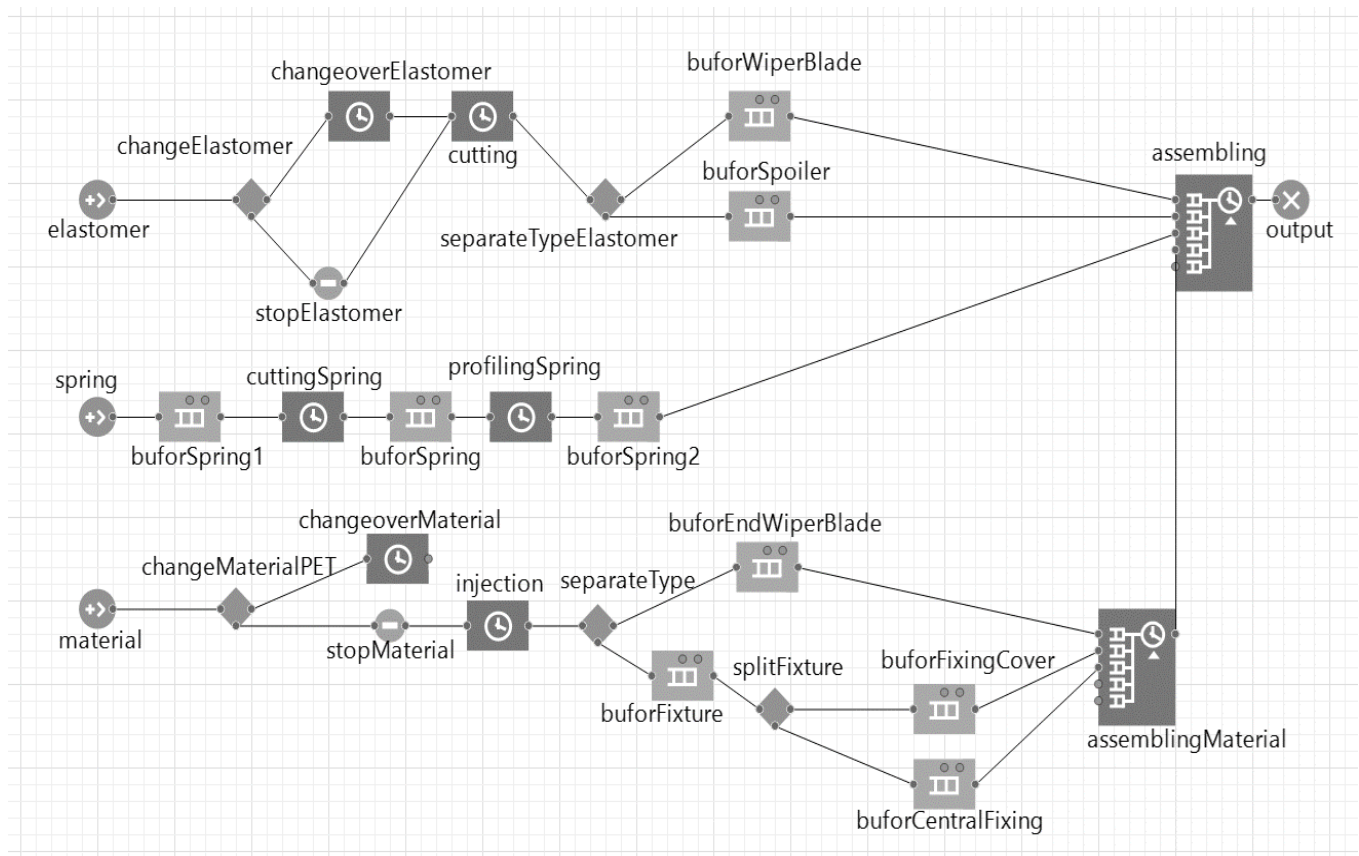

Fig. 2. Model of wiper blades production process

With a ready-made simulation you can define many different indicators and present them on charts. During the simulation it is also possible to collect data, which can then be transferred to Microsoft Excel and used for further research.

Figure 3 shows a part of the Java code mentioned above, which makes it possible to simulate a machine changeover. The code was written in the "cutting" dropdown window. The presented code allows to stop the production of feathers and start the production of spoilers, and vice versa.

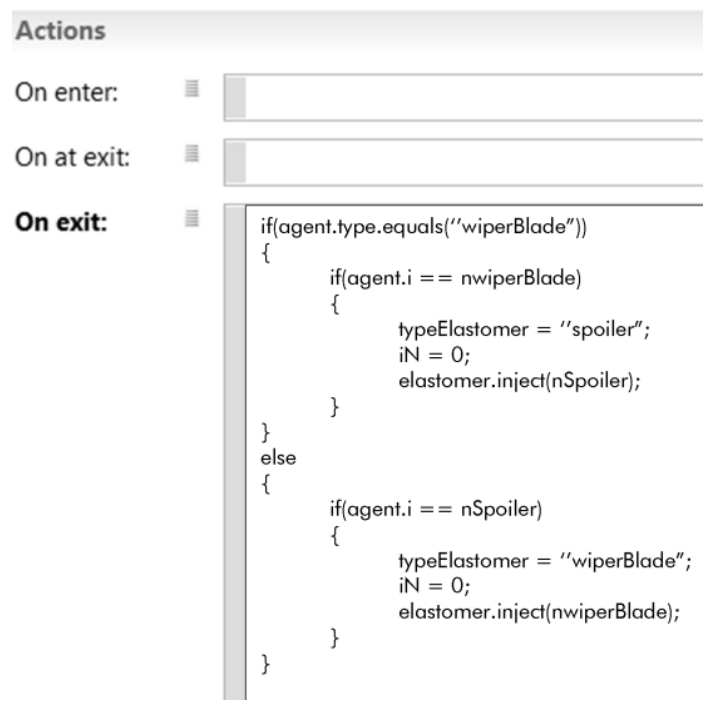

Fig. 3. Part of the Java code used to model the process
Figure 4 shows the Java code record responsible for actions on the output from the "changeoverElastomer" block, this record gives information to the program about the change of the manufactured item.

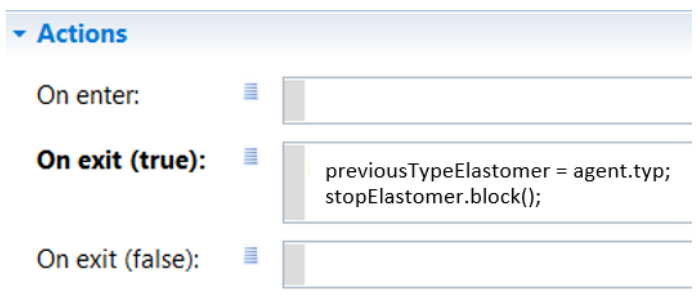

Fig. 4. Part 2 of the Java code used to model the process

The first indicator is the utilisation rate of the machine. Figure 5 shows the use of the machine to cut parts that are produced by an extruder for rubber. Initially, the use of the machine is $100 \%$, but in 30 seconds it drops to about $66 \%$, and then the use of the machine changes from 74 to $78 \%$. The average value is $76 \%$.

The second indicator is the indicator that allows you to count how many wipers have been assembled (fig. 6).

Figure 6 shows that the first wiper is only assembled in 170 seconds of simulation, due to the wait for the injection moulding machine to produce the components, as it produces two components and has to be rearmed. Within 15 minutes, 41 wipers are assembled. 


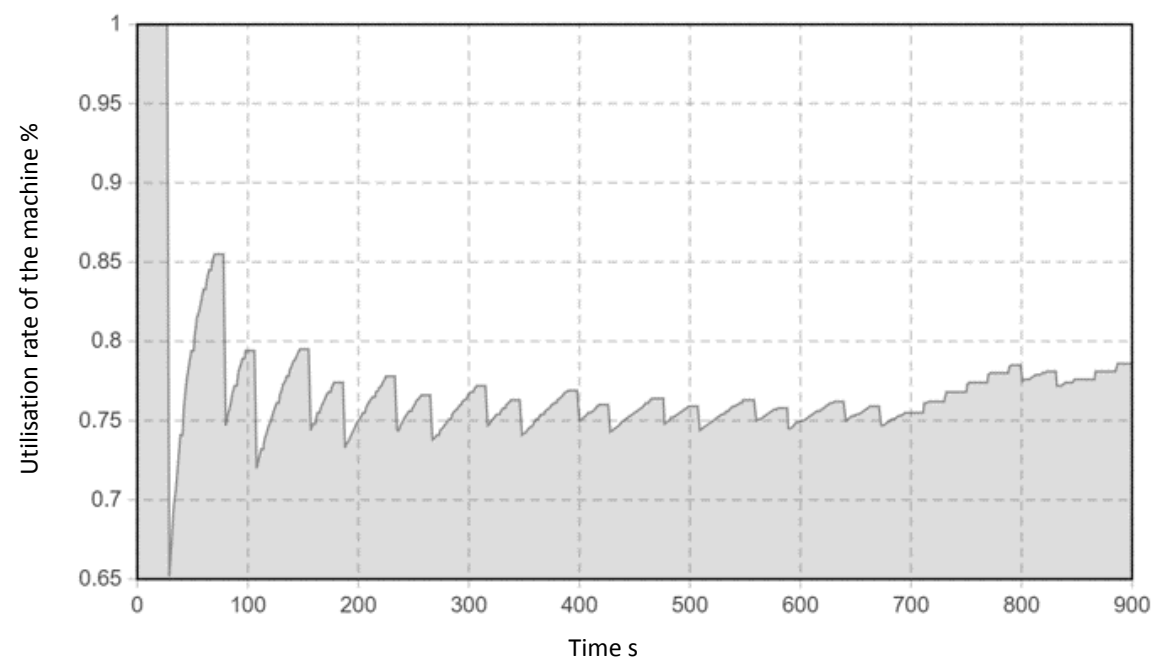

Fig. 5. Usage rate of the cutting machine

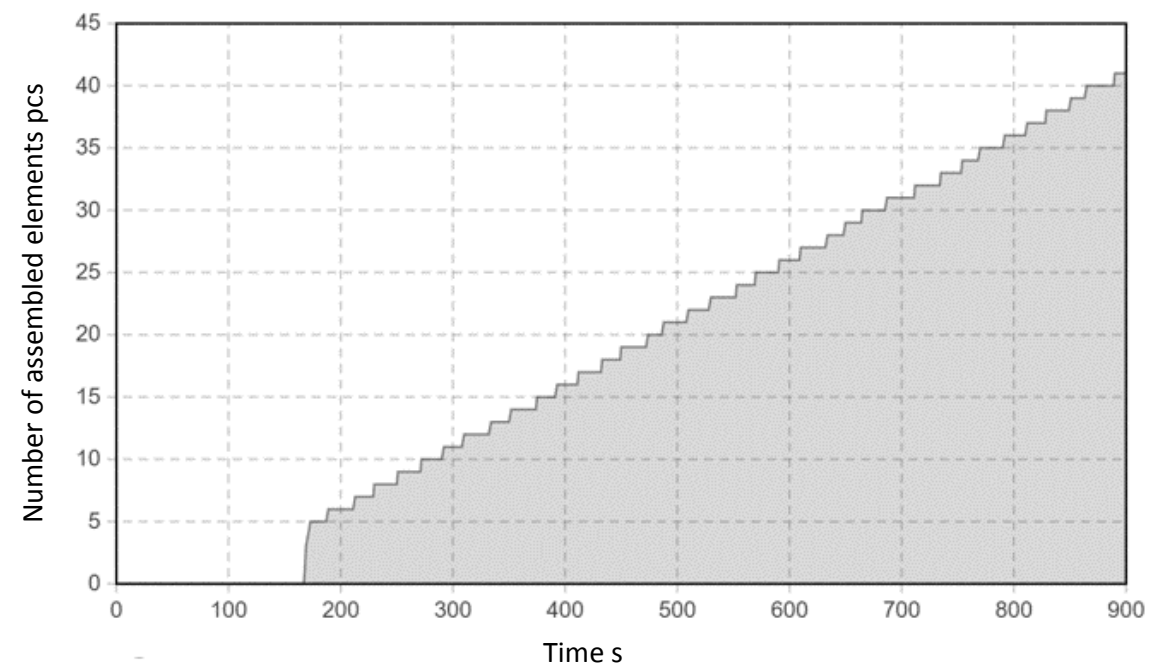

Fig. 6. Number of assembled wiper blade

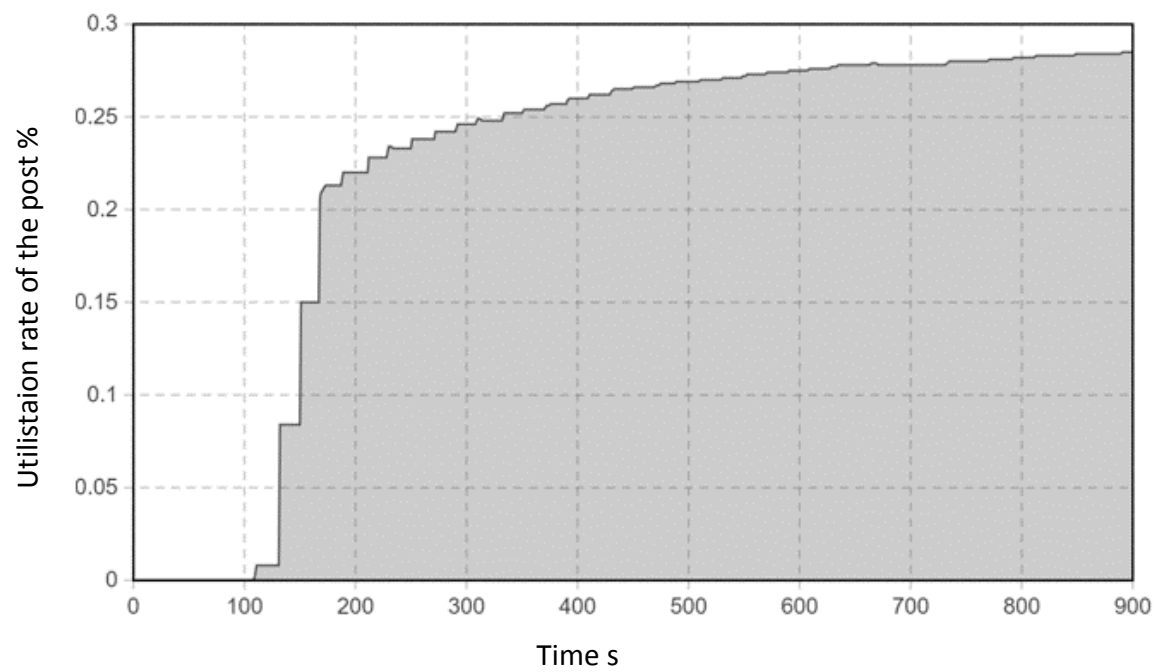

Fig. 7. Utilisation rate of the assembly station 
Another indicator (fig. 7 is the utilisation rate of the assembly station. This is very low and is due to the production of the central clamping on the plastic injection machine. A small number of elements in the warehouse causes downtime for assembly.

The figure 8 shows the use of the machine for cutting springs. Initially it is $0 \%$, because the elements enter the buffer and are then cut on the machine. The utilization of the machine increases to the total utilization, the machine runs continuously.
In the model, an agent was used, who counted how many individual elements were produced, and then the cost of production for each element was calculated. Table 2 shows a summary of the produced elements in the time that was adopted (15 minutes).

Within 15 minutes 1119 details were produced, whose cost of materials was 261.76 PLN and the weight of the plastic from which they were made was $27.84 \mathrm{~kg}$.

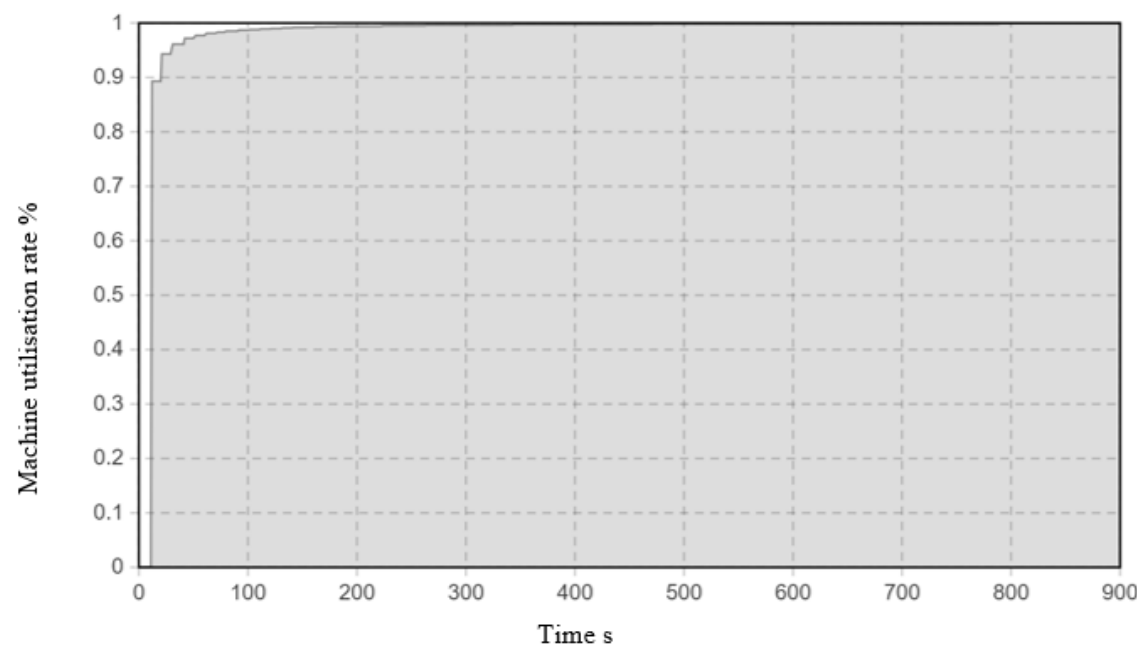

Fig. 8. Use of the machine for cutting springs

Tab. 2. Overviewof manufactured components

\begin{tabular}{|c|c|c|c|c|c|c|}
\hline L.p. & $\begin{array}{c}\text { Name of the } \\
\text { detail }\end{array}$ & $\begin{array}{l}\text { Number } \\
\text { of pieces } \\
\text { pcs }\end{array}$ & $\begin{array}{l}\text { Mass of raw } \\
\text { material per } \\
\text { price g/piece }\end{array}$ & $\begin{array}{c}\text { Cost of } 1 \\
\text { kg of raw } \\
\text { material } \\
\text { PLN }\end{array}$ & $\begin{array}{c}\text { Mass of } \\
\text { raw } \\
\text { material kg }\end{array}$ & $\begin{array}{l}\text { Manufacturing } \\
\text { cost PLN }\end{array}$ \\
\hline 1. & Feather & 100 & 20 & 12 & 2 & 24 \\
\hline 2. & Spoiler & 190 & 30 & 12 & 5,7 & 68,4 \\
\hline 3. & Spring & 89 & 60 & 4 & 5,34 & 21,36 \\
\hline 4. & $\begin{array}{c}\text { End of wiper } \\
\text { blade }\end{array}$ & 320 & 20 & 10 & 6,4 & 64 \\
\hline 5. & Fixing cover & 280 & 20 & 10 & 5,6 & 56 \\
\hline 6. & Central fixing & 140 & 20 & 10 & 2,8 & 28 \\
\hline
\end{tabular}




\section{CONCLUSIONS}

The article presents the most important information about computer simulations, system dynamics modelling, discrete events and agent modelling, which was used in the design of simulation of the wiper manufacturing process. Computer simulations are becoming one of the most important tools for planning production processes, simulation techniques are increasingly used in the design of new production systems, and also allow for the analysis of existing systems, allow for the detection of errors, or help in process optimization. The main advantages of computer simulations are the flexibility of the model (it is possible to introduce changes in a simple way), low cost and time of preparation and execution of the simulation, reliability of the results, recognition of process limitations. This process needs to be optimised because the machines are not used to their full capacity due to changeovers. The spring cutting machine is used entirely, which means that you should think of another machine that is the same, which will allow you to produce more parts.

\section{References}

1. Ciszak O. (2007). Computer-aided modelling and simulation of production processes, Scientific Papers oft he Poznań University of Technology, No. 3, 39-45 (in Polish).

2. Grigoryev I. (2016). AnyLogic in three days, 7-10, 21-23.

3. Gregor H, Haluskova M., Hromada J., Matuszek J. (1998). Simulation of Manufacturing System, Wydawnictwo Politechniki Łódzkiej, Filia w BielskuBiałej.

4. Kaczmar I. (2016). Improved economics of production structure based on simulation of discrete events.Zeszyty Naukowe Politechniki Śląskiej, 132 (in Polish)

5. Knosala R. (2017). Production engineering. Compendium of knowledge, Polskie Wydawnictwo Ekonomiczne S.A, 789-790 (in Polish).

6. Kukla S. (2007). Forecasting and simulation in the analysis of production systems. Produktywność i Innowacje, No. 1, 13-16 (in Polish)

7. Łatuszyńska M. (2011). Computer simulation methods logical classinfication test, Studies \& Proceedings of Polish Association for Knowledge Management, nr 41, 168-170 (in Polish).

8. Maciąg A., Pietroń R., Kukla S. (2013). Forecasting and simulation in the company. Polskie Wydawnictwo Ekonomiczne, 148-297 (in Polish).

9. Małopolski W. (2014). Selected issues of modelling and simulation of transport systems built from belt conveyors in Arena program. Logistyka, No. 6, 7051 (in Polish)

10. Plinta D. (2007). Optimization of production systems with the use of computer simulation. Produktywność i Innowacje, 7-10 (in Polish)

\section{Biographical note}

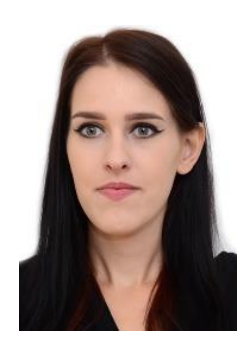

Justyna Ogorzałek received a diploma of enginee in 2018 at the Faculty of Mechanical Engineering of Koszalin University of Technology, faculty of Management and Production Engineering, specializing in Computer Technology in Production Engineering. Her scientific interested focus on the optimization of production processess using numerical simulation. During studies she was twice awarded a scholarship and was a member of the LogTech scientific society. She currently Works at Meden-Inmed as a constructor. 
